\title{
Primary Care Patients with Drug Use Report Chronic Pain and Self-Medicate with Alcohol and Other Drugs
}

\author{
Daniel P. Alford, MD, MPH', Jacqueline S. German, $M P H^{7}$, Jeffrey H. Samet, MD, MA, MPH', \\ Debbie M. Cheng, $S C D^{1,3}$, Christine A. Lloyd-Travaglini, $\mathrm{MPH}^{4}$, and Richard Saitz, MD, MPH ${ }^{1,2}$
}

\begin{abstract}
'Clinical Addiction Research and Education (CARE) Unit, Section of General Internal Medicine, Department of Medicine, Boston Medical Center and Boston University School of Medicine, Boston, MA, USA; ${ }^{2}$ Department of Community Health Sciences, Boston University School of Public Health, Boston, MA, USA; ${ }^{3}$ Department of Biostatistics, Boston University School of Public Health, Boston, MA, USA; ${ }^{4}$ Data Coordinating Center, Boston University School of Public Health, Boston, MA, USA.
\end{abstract}

\begin{abstract}
BACKGROUND: Chronic pain is common among patients with drug use disorders. The prevalence of chronic pain and its consequences in primary care patients who use drugs is unknown.

OBJECTIVES: To examine: 1) the prevalence of chronic pain and pain-related dysfunction among primary care patients who screen positive for drug use, and 2) the prevalence of substance use to self-medicate chronic pain in this population.
\end{abstract}

DESIGN: This was a cross-sectional analysis.

PARTICIPANTS: This study included 589 adult patients who screened positive for any illicit drug use or prescription drug misuse, recruited from an urban, hospitalbased primary care practice.

MAIN MEASURES: Both pain and pain-related dysfunction were assessed by numeric rating scales, and grouped as: (0) none, (1-3) mild, (4-6) moderate, (7-10) severe. Questions were asked about the use of substances to treat pain.

KEY RESULTS: Among 589 participants, chronic pain was reported by $87 \%$ (95 \% CI: 84-90 \%), with $13 \%$ mild, $24 \%$ moderate and $50 \%$ severe. Pain-related dysfunction was reported by $74 \%$ (95\% CI: 70-78\%), with $15 \%$ mild, $23 \%$ moderate, and $36 \%$ severe. Of the 576 that used illicit drugs (i.e., marijuana, cocaine, and/or heroin), $51 \%$ reported using to treat pain (95\% CI: 47-55\%). Of the 121 with prescription drug misuse, $81 \%$ (95\% CI: 74$88 \%)$ used to treat pain. Of the 265 participants who reported any heavy drinking in the past 3 months, $38 \%$ (95\% CI: 32-44\%) did so to treat pain compared to $79 \%$ (95\% CI: 68-90 \%) of the 57 high-risk alcohol users.

CONCLUSIONS: Chronic pain and pain-related dysfunction were the norm for primary care patients who screened positive for drug use, with nearly onethird reporting both severe pain and severe painrelated dysfunction. Many patients using illicit drugs, misusing prescription drugs and using alcohol reported doing so in order to self-medicate their pain. Pain needs to be addressed when patients are counseled about their substance use.

Trial Registration: clinical trials.gov NCTO0876941

Received June 15, 2015

Revised November 18, 2015

Accepted January 4, 2016

Published online January 25, 2016
KEY WORDS: substance use; primary care; chronic pain.

J Gen Intern Med 31(5):486-91

DOI: $10.1007 / \mathrm{s} 11606-016-3586-5$

(C) Society of General Internal Medicine 2016

\section{INTRODUCTION}

It is estimated that chronic pain currently affects approximately 100 million people in the US, and is one of the most common reasons patients seek medical care. ${ }^{1}$ Chronic pain is particularly common among those with drug use disorders. One survey reported that $52 \%$ of treatment-seeking, opioid dependent veterans complained of moderate to severe chronic pain. $^{2}$ Cross-sectional surveys ${ }^{3-5}$ among patients treated with medication assisted treatment (methadone, buprenorphine) report a prevalence of chronic pain ranging from $36 \%$ to $61 \%$.

According to the 2013 National Survey on Drug Use and Health, ${ }^{6}$ an estimated $9.4 \%$ of the U.S. population has used an illicit drug, including nonmedical use of prescription drugs in the past month. In one recent study, ${ }^{7} 10 \%$ of patients in an urban primary care setting screened positive for drug use (illicit and prescription misuse). However, other studies over the past decade have shown a wide range (3-26\%) of reported drug use in primary care. ${ }^{8,9}$

The prevalence and severity of chronic pain and painrelated dysfunction in patients who screen positive for the full spectrum (at-risk use to substance use disorders) of drug use (Illicit, prescription misuse) in primary care is unknown. Because alcohol, ${ }^{10}$ many illicit drugs (e.g., heroin, marijuana) and prescription opioids have analgesic properties, it is possible that patients are using these drugs to self-medicate pain. While there are numerous reasons why individuals use substances, one theory is that individuals use psychoactive substances to "self-medicate" disturbing symptoms (e.g., posttraumatic stress). ${ }^{11-13}$ The multi-site Prescription Opioid Addiction Treatment Study ${ }^{14}$ found that $83 \%$ of patients with chronic pain and prescription opioid dependence initially used opioids to treat chronic pain. If patients are self-medicating pain, then counseling interventions aimed at decreasing 
substance use, focused solely on the negative consequences of drug use, while not addressing pain symptoms, may be less effective. This issue has particular importance in light of the recently published studies that demonstrated lack of efficacy of brief intervention for unhealthy drug use in primary care. ${ }^{7,15}$

The purpose of this study is to describe the prevalence of chronic pain and pain-related dysfunction among primary care patients who screen positive for drug use. In addition, we examine the prevalence of alcohol and illicit drug use and prescription drug misuse for the purpose of self-medicating chronic pain in this population.

\section{METHODS}

\section{Study Design}

This is a cross-sectional analysis of subjects enrolled in the Assessing Screening Plus brief Intervention's Resulting Efficacy to stop drug use (ASPIRE) study (NCT00876941, see www.clinicaltrials.gov), a randomized trial assessing the efficacy of brief intervention for subjects who screened positive for illicit drug use and prescription drug misuse over the prior 3 months, in primary care. This study was approved by the Boston University Medical Center Institutional Review Board.

\section{Participants}

Study participants were recruited and enrolled from June 2009 through January 2012, from an urban, hospital-based primary care practice. Inclusion criteria were the following: (1) age 18 years or older; (2) arrived for a visit with a primary care clinician; (3) drug-specific involvement score $\geq 2$ based on self-report responses to the Alcohol, Smoking and Substance Involvement Screening Test $(\mathrm{ASSIST})^{16}$ (a minimum score of 2 means drug use once or twice in the last 3 months). Exclusion criteria were the following: (1) inability to provide contact information for two persons (to facilitate follow-up); (2) inability to interview and consent in English; (3) unwilling or unable to participate in follow-up research interviews; (4) pregnancy (self-report); (5) brief intervention by a clinical Screening, Brief Intervention and Referral to Treatment (SBIRT) program in past 3 months; (6) participation in on-site office-based opioid treatment program.

\section{Assessments}

Trained research associates conducted in-person structured interviews with all participants. They assessed both chronic pain and pain-related dysfunction using questions derived from the validated Graded Chronic Pain Scale ${ }^{17,18}$ ("in the past 3 months, on average, how intense was your pain rated on a 0 to 10 scale where 0 is no pain and 10 is pain as bad as could be" and "in the past 3 months, how much has pain interfered with your daily activities rated on a 0 to 10 scale, where 0 is no interference and 10 is unable to carry on any activities"). They also asked four questions about the use of substances to treat pain ("in the past 3 months have you used any of the following to treat your pain or discomfort - (1) alcohol, (2) drugs such as marijuana, heroin, cocaine, (3) prescription drugs without a doctor's prescription, and (4) prescription drugs used in greater amounts than prescribed").

Other assessments and variables for this analysis included demographics (age, gender, race/ethnicity, homelessness in past 3 months, current employment and years of education), substance use using the Alcohol Use Disorders Identification Test-Consumption (AUDIT-C) ${ }^{19}$ for alcohol with scores ranging from $0-12$, with $\geq 3$ for women and $\geq 4$ for men suggesting unhealthy alcohol use and $\geq 10$ suggesting alcohol dependence, the $\operatorname{ASSIST}^{16}$ for alcohol and drug use risk with substance-specific scores ranging from 0 to 39, with a higher score meaning riskier use or greater severity (drug: lowmoderate risk $2-26$, high risk $\geq 27$; alcohol low risk $0-10$, moderate risk $11-26$, high risk $\geq 27$ ), the participant's main drug ("which substance used in the past month concerns you most"), use of more than one drug in the past 3 months, misuse of prescriptions drugs in the past 3 months, injection drug use and health status using a 100-point visual analog scale (EuroQol) ${ }^{20}$ ranging from "worst" to "best" imaginable health status, depressive symptoms using the Patient Health Questionnaire (PHQ-9), ${ }^{21}$ anxiety symptoms using the Overall Anxiety Severity and Impairment Scale (OASIS), ${ }^{22}$ health care utilization (hospital, emergency department/urgent care visit past 3 months), social support ("are there people that you feel you could turn to if you were feeling bad and needed to talk to about something that was important to you"), and involvement in an automobile accident in the past 3 months.

\section{Definitions of Chronic Pain and Dysfunction}

We defined four distinct categories from both the chronic pain and the pain interfering with daily activities (dysfunction) rating scales ${ }^{23}$ : none (0), mild (1-3), moderate (4-6) and severe (7-10).

\section{Statistical Analysis}

Descriptive statistics were obtained for demographics, substance use variables, mental and physical health variables, and health care utilization for the overall sample, and stratified by chronic pain severity (i.e., no pain, mild, moderate, or severe pain). Bivariate associations were assessed using chi-square tests, Fisher's exact tests, or ANOVA as appropriate. We estimated the prevalence of chronic pain, pain-related dysfunction and use of substances to treat pain along with their corresponding $95 \%$ confidence intervals. Exact binomial confidence intervals were used in cases where $n p(1-p)<5$, where $p$ is the observed sample proportion. Analyses were performed using SAS software (version 9.3; SAS Institute, Cary, NC). 


\section{RESULTS}

\section{Demographic Characteristics (Table 1)}

The cohort included 589 patients at an urban, academic medical center's primary care practice who screened positive for drug use (illicit, prescriptions misuse) by scoring $\geq 2$ on the ASSIST screening tool (for the main drug). During study enrollment (May 2009 - January 2012), 25,302 patients were screened for drug use as part of a clinical program in primary care, and 2,624 patients $(10 \%)$ were found positive for any drug use in the past 3 months. Of those, 1,018 were found eligible when research staff were available to enroll subjects for the original RCT study described by Saitz et al. ${ }^{7}$ with a total of 589 patients consented and enrolled; they were $32 \%$ female, $70 \%$ black, with a mean age of 41 years.

\section{Prevalence of Pain and Pain-Related Dysfunction (Table 1)}

Of the 589 participants, $87 \%$ (95\% CI: 84-90\%) reported having any chronic pain, with $13 \%$ mild, $24 \%$ moderate and $50 \%$ severe. Those with both high-risk drug use (ASSIST $\geq$ 27) and low- to moderate-risk drug use (ASSIST 2-26) had similarly high prevalence of severe pain, $45 \%$ and $51 \%$ respectively. Descriptive statistics and bivariate analyses suggested that those with severe pain were older, more likely to be Hispanic ethnicity, less likely to have graduated from high school, more likely to be currently unemployed, had lower overall health status, more depressive and anxiety symptoms, were more likely to have a hospitalization and emergency department visit in the past 3 months, and were less likely to have used alcohol in the past year (Table 1). Pain-related dysfunction was reported by $74 \%$ (95\% CI: 70-78\%) of participants with $15 \%$ mild, $23 \%$ moderate, and $36 \%$ severe. Concurrent severe pain and severe dysfunction was found in $32 \%$.

\section{Prevalence of Using Substances to Self-Medicate Chronic Pain (Table 2)}

Of the 576 participants who reported any marijuana, cocaine or heroin use in the last 3 months, $51 \%$ (95 \% CI: $47-55 \%$ ) reported using one or more of these drugs to treat their pain. Of those that used only one drug, either marijuana $(n=341)$, cocaine $(n=43)$ or heroin $(n=7), 43 \%(95 \%$ CI: $38-49 \%$ ), 42 \% (95 \% CI: 27-57 \%) and $71 \%$ (95 \% CI: 29 $96 \%)$ respectively, did so to treat their pain.

Of the 121 participants who misused prescription drugs (i.e., opioids, sedatives, stimulants) $81 \%$ (95\% CI: $74-$ $88 \%$ ) misused the drug to treat their pain. Among these subjects, $69 \%$ (95\% CI: 60-77\%) reported using without a prescription to treat pain and $32 \%$ (95\% CI: $24-41 \%)$ reported using more drug than prescribed to treat pain.
Of the 265 participants who reported any heavy drinking in the past 3 months, $38 \%$ (95\% CI: $32-44 \%)$ did so to treat pain, compared to $79 \%$ (95\% CI: 68-90\%) of the 57 participants who were considered to be high-risk drinkers (ASSIST $\geq 27$ ) Among the 371 participants with unhealthy alcohol use in the past year (AUDIT-C score $\geq 3$ for women and $\geq 4$ for men), $35 \%$ (95\% CI: $30-40 \%$ ) did so to treat pain, compared to $61 \%$ (95\% CI: 52-70\%) of the 114 with likely alcohol dependence (AUDIT-C $\geq 10$ ).

\section{DISCUSSION}

While approximately one-third of the U.S. population ${ }^{24}$ and one-fifth of patients seeking primary care have chronic pain, ${ }^{25}$ $87 \%$ of our cohort of primary care patients who screened positive for drug use reported chronic pain. Almost half of these patients reported severe pain and approximately onethird reported both severe pain and severe pain-related dysfunction. Persons with addiction and pain have a "syndrome of pain facilitation," where pain is worsened by withdrawalrelated sympathetic nervous system arousal, sleep disturbances, and affective changes. ${ }^{26}$ While previous studies have shown that up to $60 \%$ of patients with drug use disorders have chronic pain, ${ }^{3,4}$ our cohort found that patients with lower risk drug use (ASSIST <27) had similar levels of pain as those with higher risk drug use (ASSIST $\geq 27$ ).

Characteristics associated with more severe pain included less education and higher unemployment, more non-primary care-based healthcare utilization (emergency department/ urgent care visits, hospitalizations), older age, Hispanic ethnicity, lower overall health status and more symptoms of depression and anxiety and a lower proportion reporting any past year alcohol use. The associations between chronic pain and older age, ${ }^{27}$ depression and anxiety ${ }^{28}$ and increased healthcare utilization ${ }^{29}$ have been well described. While the association between pain and unemployment, less education and race is not clear, ${ }^{30}$ these characteristics are associated with lower socioeconomic status, which has been associated with increased prevalence and severity of chronic pain. ${ }^{31}$ While our study found a higher prevalence of chronic pain in Hispanic participants, this is counter to a large U.S. epidemiologic study that found significantly less chronic pain in Hispanics compared to Non-Hispanics. ${ }^{27}$ However, Hispanics are at higher risk for painful conditions given their lower overall socioeconomic status and higher rates of obesity. ${ }^{1}$ Hispanics of Puerto Rican decent have been shown to have higher rates of chronic back and neck pain. ${ }^{32}$

Individuals use substances for many reasons, including peer pressure, sensation seeking and self-medication of medical and psychiatric symptoms. ${ }^{33}$ In this study, it was common for patients to attribute their substance use to treating symptoms of pain. Over half of the cohort using illicit drugs, twothirds misusing prescription drugs without a prescription, and one-third using their prescription in greater amounts than 
Table 1 Chronic Pain Severity by Characteristics of Primary Care Patients with Drug Use Identified by Universal Screening

\begin{tabular}{|c|c|c|c|c|c|c|c|}
\hline Characteristic & & $\begin{array}{l}\text { Overall } \\
N=589\end{array}$ & $\begin{array}{l}\text { No Pain } \\
N=76 \\
(12.9 \%)\end{array}$ & $\begin{array}{l}\text { Mild Pain } \\
N=76 \\
(12.9 \%)\end{array}$ & $\begin{array}{l}\text { Mod. Pain } \\
N=144 \\
(24.5 \%)\end{array}$ & $\begin{array}{l}\text { Severe Pain } \\
N=293 \\
(49.8 \%)\end{array}$ & $p$ value \\
\hline \multicolumn{8}{|l|}{ Demographics } \\
\hline Age & Mean (SD) & $41.3(12.4)$ & $37.5(12.6)$ & $38.9(13.2)$ & $40.5(12.7)$ & $43.3(11.6)$ & $<0.001$ \\
\hline \multicolumn{7}{|l|}{ Gender } & \multirow[t]{3}{*}{0.21} \\
\hline - Male & $N(\%)$ & $402(68.3)$ & $59(77.6)$ & $54(71.1)$ & $93(64.6)$ & $196(66.9)$ & \\
\hline - Female & $N(\%)$ & $187(31.8)$ & $17(22.4)$ & $22(29.0)$ & $51(35.4)$ & $97(33.1)$ & \\
\hline \multicolumn{7}{|l|}{ Race/ethnicity } & \multirow[t]{5}{*}{$0.008^{*}$} \\
\hline - Black & $N(\%)$ & $404(69.7)$ & $50(67.6)$ & $53(69.7)$ & $101(71.1)$ & $200(69.4)$ & \\
\hline - Hispanic & $N(\%)$ & $53(9.1)$ & $6(8.1)$ & $2(2.6)$ & $7(4.9)$ & $38(13.2)$ & \\
\hline - White & $N(\%)$ & $115(19.8)$ & $15(20.3)$ & $19(25.0)$ & $33(23.2)$ & $48(16.7)$ & \\
\hline - Other & $N(\%)$ & $8(1.4)$ & $3(4.1)$ & $2(2.6)$ & $1(0.7)$ & $2(0.7)$ & \\
\hline High school graduate & $N(\%)$ & $416(70.6)$ & $65(85.5)$ & $62(81.6)$ & $102(70.8)$ & $187(63.8)$ & $<0.001$ \\
\hline Current employment & $N(\%)$ & $163(27.7)$ & $31(40.8)$ & $34(44.7)$ & $40(27.8)$ & $58(19.8)$ & $<0.001$ \\
\hline Current homelessness past 3 months & $N(\%)$ & $95(16.1)$ & $10(13.2)$ & $10(13.2)$ & $23(16.0)$ & $52(17.8)$ & 0.67 \\
\hline \multicolumn{8}{|l|}{ Physical Health } \\
\hline Health status & Mean (SD) & $70.2(20.1)$ & $80.8(15.8)$ & $74.9(17.2)$ & $70.5(18.6)$ & $66.1(21.3)$ & $<0.001$ \\
\hline \multicolumn{8}{|l|}{$\left(\right.$ EuroQol $\left.^{1}\right)$} \\
\hline Any hospitalization past 3 months & $N(\%)$ & $84(14.3)$ & $3(4.0)$ & $10(13.2)$ & $18(12.5)$ & $53(18.1)$ & 0.01 \\
\hline Any ED/Urgent care past 3 months & $N(\%)$ & $215(36.5)$ & $18(23.7)$ & $18(23.7)$ & $51(35.4)$ & $128(43.7)$ & $<0.001$ \\
\hline Automobile accident past 3 months & $N(\%)$ & $21(3.6 \%)$ & $6(7.9)$ & $2(2.6)$ & $5(3.5)$ & $8(2.7)$ & $0.21^{\dagger}$ \\
\hline \multicolumn{8}{|l|}{ Mental Health } \\
\hline Depressive symptoms $\left(\mathrm{PHQ}^{2} \geq 10\right)$ & $N(\%)$ & $202(34.3)$ & $15(19.7)$ & $17(22.4)$ & $42(29.2)$ & $128(43.7)$ & $<0.001$ \\
\hline Anxiety symptoms $\left(\mathrm{OASIS}^{3} \geq \overline{8}\right)$ & $N(\%)$ & $193(32.8)$ & $15(19.7)$ & $19(25.0)$ & $44(30.6)$ & $115(39.3)$ & 0.003 \\
\hline Positive social support & $N(\%)$ & $519(88.1)$ & $70(92.1)$ & $72(94.7)$ & $127(88.2)$ & $250(85.3)$ & 0.09 \\
\hline \multicolumn{8}{|l|}{ Alcohol Use } \\
\hline Any alcohol use in past year & $N(\%)$ & $522(88.6)$ & $71(93.4)$ & $68(89.5)$ & $134(93.1)$ & $249(85.0)$ & 0.04 \\
\hline AUDIT-C positive ${ }^{4}$ (Unhealthy Use) & $N(\%)$ & $371(63.0)$ & $53(69.7)$ & $47(61.8)$ & $93(64.6)$ & $178(60.8)$ & 0.51 \\
\hline AUDIT-C $\geq 10{\text { (Dependence })^{5}}^{5}$ & $N(\%)$ & $114(19.4)$ & $13(17.1)$ & $13(17.1)$ & $35(24.3)$ & $53(18.1)$ & 0.38 \\
\hline Heavy alcohol use in past 3 months & $N(\%)$ & $265(45.0)$ & $39(51.3)$ & $37(48.7)$ & $66(45.8)$ & $123(42.0)$ & 0.43 \\
\hline \multicolumn{7}{|l|}{ ASSIST $^{6}$ score for alcohol } & \multirow[t]{4}{*}{0.34} \\
\hline • Low-risk use (0-10) & $N(\%)$ & $448(76.1)$ & $61(80.3)$ & $58(76.3)$ & $102(70.8)$ & $227(77.5)$ & \\
\hline - Moderate-risk use (11-26) & $N(\%)$ & $84(14.3)$ & $8(10.5)$ & $13(17.1)$ & $28(19.4)$ & $35(12.0)$ & \\
\hline • High-risk use $(\geq 27)$ & $N(\%)$ & $57(9.7)$ & $7(9.2)$ & $5(6.6)$ & $14(9.7)$ & $31(10.6)$ & \\
\hline \multicolumn{8}{|l|}{ Drug Use } \\
\hline Misuse of prescription drugs & $N(\%)$ & $121(20.5)$ & $10(13.2)$ & $14(18.4)$ & $30(20.8)$ & $67(22.9)$ & 0.29 \\
\hline Use of more than one drug & $N(\%)$ & $182(30.9)$ & $19(25.0)$ & $16(21.1)$ & $53(36.8)$ & $94(32.1)$ & 0.06 \\
\hline Injection Drug Use & $N(\%)$ & $67(11.5)$ & $9(12.0)$ & $6(8.1)$ & $18(12.7)$ & $34(11.6)$ & 0.79 \\
\hline \multicolumn{7}{|l|}{ Main drug } & \multirow{4}{*}{0.18} \\
\hline - Marijuana & $N(\%)$ & $374(64.8)$ & $55(73.3)$ & $57(75.0)$ & $84(60.0)$ & $178(62.2)$ & \\
\hline - Cocaine & $N(\%)$ & $107(18.5)$ & $12(16.0)$ & $10(13.2)$ & $31(22.1)$ & $54(18.9)$ & \\
\hline • Opioids (heroin, Rx) & $N(\%)$ & $96(16.6)$ & $8(10.7)$ & $9(11.8)$ & $25(17.9)$ & $54(18.9)$ & \\
\hline \multirow{3}{*}{$\begin{array}{l}\text { ASSIST }^{6} \text { score for Drugs } \\
\text { - Low-mod-risk use }(2-26) \\
\text { - High-risk use }(\geq 27)\end{array}$} & & & & & & & \multirow[t]{3}{*}{0.31} \\
\hline & $N(\%)$ & $492(83.5)$ & $65(85.5)$ & $65(85.5)$ & $113(78.5)$ & $249(85.0)$ & \\
\hline & $N(\%)$ & $97(16.5)$ & $11(14.5)$ & $11(14.5)$ & $31(21.5)$ & $44(15.0)$ & \\
\hline
\end{tabular}

† Fisher's Exact Test

* Monte Carlo estimate for the Exact Test

${ }^{I}$ EuroQol-Health status score, range 0-100; higher score indicates better self-reported health

2 PHQ9 - Patient Health Questionnaire, range 0-27; higher score indicates worse depressive symptoms (minimal 0-4, mild 5-9, moderate 10-14, moderately severe 15-19, severe 20-27)

${ }^{3}$ OASIS - Overall Anxiety Severity and Impairment Scale, range 0-20; higher score indicates worse anxiety symptoms

${ }^{4,5}$ AUDIT-C - The Alcohol Use Disorders Identification Test Consumption for past year use, range 0-12, with $\geq 3$ for women and $\geq 4$ for men suggesting unhealthy alcohol use, with $\geq 10$ suggesting alcohol dependence

${ }_{6}^{6}$ ASSIST - The Alcohol, Smoking and Substance Involvement Screening Test for past 3 month use, substance-specific scores range 0-39; higher score indicates riskier use/greater severity

prescribed, reported doing so to treat pain. Among those with any recent heavy alcohol use, over one-third drank to treat their pain, compared to over three-quarters of those who met the criteria for current high-risk alcohol use. Using substances to self-medicate psychiatric symptoms has been described for decades. In addition, the association between substance use and chronic pain has been well described. ${ }^{34,35}$ Appreciating this association has important implications when addressing both the patient's substance use as well as their pain. Studies $^{35,36}$ have found that chronic pain was independently associated with relapse to substance use after detoxification, but not associated with worse office-based buprenorphine treatment outcomes. ${ }^{37}$ If drugs are being used to selfmedicate pain, patients may be reluctant to decrease, stop or remain abstinent if their pain symptoms are not adequately managed. This issue of self-medicating pain is particularly relevant with the recent studies showing lack of efficacy of brief interventions to decrease drug use in primary care. ${ }^{38}$ Brief interventions, especially those performed by allied health staff, often focus on the association between substance use and negative health and life consequences ${ }^{39}$; they often do not address alternative approaches to treating symptoms such as chronic pain. Addressing pain symptoms is complicated for the most experienced physician and is outside the skill set of 
Table 2 Substance Use and Use of Substances to Treat Pain among Primary Care Patients with Drug Use

\begin{tabular}{|c|c|c|}
\hline Substance Use & $\begin{array}{l}\text { Number reporting use for pain/number } \\
\text { reporting use of specific drug }\end{array}$ & $\begin{array}{l}\text { \% Use for pain } \\
(95 \% \text { CI) }\end{array}$ \\
\hline \multicolumn{3}{|l|}{ Illicit drug use and prescription drug misuse in the past 3 months } \\
\hline Any illicit drug (marijuana, cocaine and/or heroin) use $(N=576)$ & $296 / 576$ & $51 \%(47-55 \%)$ \\
\hline Marijuana use only $(N=341)$ & $148 / 341$ & $43 \%(38-49 \%)$ \\
\hline Cocaine use only $(N=43)$ & $18 / 43$ & $42 \%(27-57 \%)$ \\
\hline Heroin use only $(N=7)$ & $5 / 7$ & $71 \%(29-96 \%)$ \\
\hline Prescription drug misuse $(N=121)$ & $98 / 121$ & $81 \%(74-88 \%)$ \\
\hline \multicolumn{3}{|l|}{ Alcohol use in past 3 months } \\
\hline Any heavy drinking [women: $>3$, men: $>4$ standard drinks] $(N=265)$ & $100 / 265$ & $38 \%(32-44 \%)$ \\
\hline High-risk alcohol use [ASSIST $\geq 27](N=57)$ & $45 / 57$ & $79 \%(68-90 \%)$ \\
\hline \multicolumn{3}{|l|}{ Alcohol use in past year } \\
\hline AUDIT-C positive for unhealthy alcohol use [women: $\geq 3$, men: $\geq 4](N=371)$ & $129 / 371$ & $35 \%(30-40 \%)$ \\
\hline AUDIT-C positive for alcohol dependence [AUDIT-C $\geq 10](N=114)$ & $69 / 114$ & $61 \%(52-70 \%)$ \\
\hline
\end{tabular}

most allied health staff performing brief intervention counseling. Brief interventions focusing solely on the harmful effects of an illicit or misused drug may be ignored or disregarded if the patient perceives the drug as necessary to treat a symptom.

This study has some important limitations. Since the cohort includes only patients at an urban, hospital-based primary care practice who screened positive for drug use in the past 3 months and were enrolled in a clinical trial, it may not be generalizable to the larger population of people who use drugs. This limitation in external validity likely applies more to the prevalence of drug use than it would apply to the prevalence of pain among those using drugs; we have no hypothesis about why that prevalence would differ in other populations. Furthermore, we included a wide spectrum of drug use, ranging from one day's use in the last 3 months to multiple uses every day, including use of marijuana, cocaine, heroin and misuse of prescription drugs, and spanning the ASSIST risk scores from 2 (low risk of problems) to 27 or greater (likely to be substance use disorder). This gives the study the broadest applicability to all levels of drug use severity. As with any cross-sectional analysis, we analyzed data from one point in time and thus cannot assume causality; the purpose of the study was to describe prevalences of interest. Lastly, this was a secondary analysis and not the primary focus of the original study, and as such, pain data were collected using unidimensional numeric rating scales derived from the Graded Chronic Pain Scale. ${ }^{17}$ Had this been the primary question of the original study, we would have chosen a more comprehensive, multidimensional pain and functional assessment that would have further characterized pain symptoms. We believe that future studies should examine in greater detail, with prospective vision, the relationships that were observed in our findings.

The high prevalence of chronic pain in patients who screen positive for drug use in primary care highlights the importance of assessing and managing chronic pain in this population. While there are many reasons why individuals use psychoactive substances, our finding of substance use in primary care patients to self-medicate pain has important implications for how brief counseling interventions are performed. To maximize the benefits of brief interventions in such patients, it is prudent to address the patient's substance use and pain complaints concurrently. There is growing evidence that comanaging pain and opioid use disorders with behavioral treatments can be effective. ${ }^{40}$ It is in unclear if comanagement will improve the efficacy of brief counseling interventions for nontreatment-seeking patients, identified by universal screening in general healthcare settings, the majority of whom will have unhealthy substance use that does not meet criteria for a use disorder. ${ }^{41}$ However, it seems unlikely that individuals using substances to self-medicate pain, even if they have additional reasons for such use, will discontinue substance use if their pain symptoms are not adequately addressed with alternative approaches.

Acknowledgements: Funders: The ASPIRE study was funded by an award from the National Institute on Drug Abuse (RO1 DA025068), a portion of which was supported by the Center for Substance Abuse Treatment, SAMHSA. This study also received funding from SAMHSA (TIO18311) through a Massachusetts Department of Public Health (MDPH) contract with Boston Medical Center (INTF2330M04W76112076). Additional funding was received from the National Center for Research Resources (UL1RR025771). Neither the National Institutes of Health (NIH) nor SAMHSA nor MDPH contributed to the design and conduct of the study; collection, management, analysis, and interpretation of the data; and preparation, review, or approval of the manuscript; and decision to submit the manuscript for publication. This paper has not been previously published or presented in abstract form.

Corresponding Author: Daniel P. Alford, MD, MPH; Clinical Addiction Research and Education (CARE) Unit, Section of General Internal Medicine, Department of MedicineBoston Medical Center and Boston University School of Medicine, 801 Massachusetts Avenue, 2nd floor, Boston, MA 02118, USA (e-mail: Dan.Alford@bmc.org).

\section{Compliance with Ethical Standards:}

Conflicts of Interest: The authors declare that they do not have a conflict of interest.

\section{REFERENCES}

1. Institute of Medicine Committee on Advancing Pain Research Care and Education. The National Academies Collection: Reports funded by National Institutes of Health. Relieving Pain in America: A Blueprint for Transforming Prevention, Care, Education, and Research. Washington (DC): National Academies Press (US) National Academy of Sciences; 2011. 
2. Trafton JA, Oliva EM, Horst DA, Minkel JD, Humphreys $\mathrm{K}$. Treatment needs associated with pain in substance use disorder patients: implications for concurrent treatment. Drug Alcohol Depend. 2004;73:2331.

3. Rosenblum A, Joseph H, Fong C, Kipnis S, Cleland C, Portenoy RK. Prevalence and characteristics of chronic pain among chemically dependent patients in methadone maintenance and residential treatment facilities. JAMA. 2003;289:2370-2378.

4. Jamison RN, Kauffman J, Katz NP. Characteristics of methadone maintenance patients with chronic pain. J Pain Symptom Manag. 2000; 19:53-62.

5. Barry DT, Savant JD, Beitel M, Cutter CJ, Moore BA, Schottenfeld RS, Fiellin DA. Pain and associated substance use among opioid dependent individuals seeking office-based treatment with buprenorphine-naloxone: a needs assessment study. Am J Addict. 2013;22(3):212-217.

6. Substance Abuse and Mental Health Services Administration. Available at http://www.samhsa.gov/data/population-data-nsduh. Accessed December 15, 2015.

7. Saitz R, Palfai TA, Cheng DM, Alford DP, Bernstein JA, Lloyd-Travglini CA, Meli SM, Chaisson CE, Samet JH. Screening and brief intervention for drug use in primary care: the ASPIRE randomized clinical trial. JAMA. 2014;312(5):502-513.

8. McNeely J, Strauss SM, Saitz R, Cleland CM, Palamar JJ, Rotrosen J, Gourevitch MN. A brief patient self-administered substance use screening tool for primary care: two-site validation study of the Substance Use Brief Screen (SUBS). Amer J Med. 2015. doi:10.1016/j. amjmed.2015.02.007.

9. Manwell LB, Fleming MF, Johnson K, Barry KL. Tobacco, alcohol, and drug use in a primary care sample: 90-day prevalence and associated factors. J Addict Dis. 1998;17(1):67-81.

10. Woodrow KM, Eltherington LG. Feeling no pain: alcohol as an analgesic. Pain. 1988;32(2):159-163.

11. Harris KM, Edlund MJ. Self-medication of mental health problems: New evidence from a national survey. Health Serv Res. 2005;40(1):117-134.

12. Chilcoat HD, Breslau N. Posttraumatic stress disorder and drug disorders: testing causal pathways. Arch Gen Psychiatry. 1998;55(10):913-917.

13. Mariani JJ, Khantzian EJ, Levin FR. The self-medication hypothesis and psychostimulant treatment of cocaine dependence: an update. Am J Addict. 2014;23(2): 189-193.

14. Weiss RD, Potter JS, Griffin ML, McHugh RK, Haller D, Jacobs $\mathbf{P}$ Gardin J, Fischer D, Rosen KD. Reasons for opioid use among patients with dependence on prescription opioids: the role of chronic pain. J Subst Abus Treat. 2014;47(2): 140-145.

15. Roy-Byrne $\mathbf{P}$, Bumgardner $\mathbf{K}$, Krupski A, Dunn $\mathbf{C}$, Ries $\mathbf{R}$, Donovan D, et al. Brief intervention for problem drug use in safety-net primary care settings: a randomized clinical trial. JAMA. 2014;312(5):492501.

16. Humeniuk R, Ali R, Babor TF, et al. Validation of the alcohol, smoking and substance involvement screening test (ASSIST). Addiction. 2008;103(6): 1039-1047.

17. Von Korff M, Ormel J, Keefe FJ, Dworkin SF. Grading the severity of chronic pain. Pain. 1992;50(2):133-149.

18. Von Korff M. Assessment of chronic pain in epidemiological and health services research: empirical bases and new directions. In: Turk DC, Melzack R, eds. Handbook of pain assessment. 3rd ed. New York: Guilford Press; 2011:455-473.

19. Bush K, Kivlahan DR, McDonell MB, Fihn SD, Bradley KA. The AUDIT alcohol consumption questions (AUDIT-C): an effective brief screening test for problem drinking. Arch Intern Med. 1998;158(16):1789-1795.

20. Euroßol Group. EuroGol-a new facility for the measurement of healthrelated quality of life. Health Policy. 1990;16(3):199-208.
21. Kroenke K, Spitzer RL, Williams JBW. The PHQ-9: validity of a brief depression severity measure. J Gen Intern Med. 2001;16(9):606-613.

22. Norman SB, Cissel SH, Means-Christensen AJ, Stein M. Development and validation of an overall anxiety severity and impairment scale (OASIS). Depress Anxiety. 2006;23(4):245-249.

23. Breivik H, Borchgrevink PC, Allen SM, et al. Assessment of pain. $\mathrm{Br} J$ Anaesth. 2008;101(1):17-24.

24. Dzau VJ, Pizzo PA. Relieving pain in america: insights from an institute of medicine committee. JAMA. 2014;312(15):1507-1508.

25. Gureje O, Von Korff M, Simon GE, Gater R. Persistent pain and wellbeing: a world health organization study in primary care. JAMA. 1998;280(2): 147-151.

26. Savage SR, Schofferman J. Pharmacological therapies of pain in drug and alcohol addictions. In: Miller N, Gold M, eds. Pharmacological therapies for drug and alcohol addictions. New York: Dekker; 1995:373409.

27. Kennedy J, Roll JM, Schraudner T, Murphy S, McPherson S. Prevalence of persistent pain in the US adult population: new data from the 2010 national health interview survey. J Pain. 2014;15(10):979-984.

28. Cheatle MD, Gallagher RM. Chronic pain and comorbid mood and substance use disorders: a biopsychosocial treatment approach. Curr Psychiatry Rep. 2006;8(5):371-376.

29. Gore M, Sadosky A, Stacey BR, Tai KS, Leslie D. The burden of chronic low back pain: clinical comorbidities, treatment patterns, and health care costs in usual care settings. Spine. 2012;37(11):E668-E677.

30. Elliott AM, Smith BH, Hannaford PC, Smith WC, Chambers WA. The course of chronic pain in the community: results of a 4-year follow-up study. Pain. 2002;99(1):299-307.

31. Poleshuck E, Green C. Socioeconomic disadvantage and pain. Pain. 2008;136:235-238.

32. Bui Q, Doescher M, Takeuchi D, Taylor V. Immigration, acculturation and chronic back and neck problems among Latino-Americans. J Immigr Minor Health. 2011;13(2): 194-201.

33. Boys A, Marsden J, Strang J. Understanding reasons for drug use amongst young people: a functional perspective. Health Educ Res. 2001;16(4):457-469.

34. Gonzalez JMR, Walters ST, Lerch J, Taxman FS. The relationship between drug use, drug-related arrests, and chronic pain among adults on probation. J Subst Abus Treat. 2015;53:33-38.

35. Potter JS, Chakrabarti A, Domier CP, Hillhouse MP, Weiss RD, Ling W. Pain and continued opioid use in individuals receiving buprenorphinenaloxone for opioid detoxification: secondary analyses from the clinical trials network. J Subst Abus Treat. 2010;38:S80-S86.

36. Larson MJ, Paasche-Orlow M, Cheng DM, Lloyd-Travaglini C, Saitz $\mathbf{R}$ Samet JH. Persistent pain is associated with substance use after detoxification: a prospective cohort analysis. Addiction. 2007;102(5):752760 .

37. Fox AD, Sohler NL, Starrels JL, Ning Y, Giovanniello A, Cunningham Co. Pain is not associated with worse office-based buprenorphine treatment outcomes. Subst Abus. 2012;33(4):361-365.

38. Hingson R, Compton WM. Screening and brief intervention and referral to treatment for drug use in primary care: back to the drawing board. JAMA. 2014;312(5):488-489.

39. Samet JH, Rollnick S, Barnes H, Beyond CAGE. A brief clinical approach after detection of substance abuse. Arch Intern Med. 1996;156(20):22872293.

40. Barry DT, Cutter CJ, Beitel M, Liong C, Schottenfeld RS. Cognitivebehavioral therapy and educational counseling for chronic pain and opioid dependence. Drug Alcohol Depend. 2015;146:e218-e219.

41. Madras BK, Compton WM, Avula D, Stegbauer T, Stein JB, Clark HW. Screening, brief interventions, referral to treatment (SBIRT) for illicit drug and alcohol use at multiple healthcare sites: comparison at intake and 6 months later. Drug Alcohol Depend. 2009;99(1):280-295. 